\title{
ДИФФЕРЕНЦИАЦИЯ РЕГИОНОВ РОССИИ ПО УРОВНЮ БЮДЖЕТНОЙ ОБЕСПЕЧЕННОСТИ: ПРОБЛЕМЫ И ПУТИ РЕШЕНИЯ"
}

\author{
(c) 2021 Токаева Светлана Константиновна \\ кандидат экономических наук, доцент кафедры «Менеджмент» \\ Финансовый университет при Правительстве Российской Федерации, Владикавказский филиал, \\ РСО-Алания, Владикавказ \\ доцент кафедры «Бухгалтерский учет и налогообложение» \\ Северо-Осетинский государственный университет им. К. Л. Хетагурова, РСО-Алания, Владикавказ \\ E-mail:sks_ts@mail.ru \\ (c) 2021 Туаева Лали Александровна \\ кандидат экономических наук, доцент кафедры «Менеджмент» \\ Финансовый университет при Правительстве Российской Федерации, Владикавказский филиал, \\ РСО-Алания, Владикавказ \\ E-mail: LATuaeva@fa.ru
}

Высокая степень неравенства регионов России, проявляющаяся в широком разбросе социальноэкономических показателей (ВРП, объемы инвестиций в основной капитал, средние значения доходов населения, объемы производства, численность и структура населения, уровень занятости и др.), определяют параметры и характер формирования консолидированных бюджетов субъектов РФ. Сформировавшиеся к настоящему времени тренды развития территориальных экономических систем характеризуются растущими межрегиональными диспропорциями, усугубляя ассиметричный тип развития национальной экономики.

В статье исследуется проблематика формирования бюджетов территорий, механизмов финансового выравнивания бюджетной обеспеченности регионов России, в контексте снижения межрегиональной дифференциации. На основании полученных выводов определены направления совершенствования межбюджетного регулирования.

Ключевые слова: бюджетная обеспеченность, бюджетная устойчивость, государственный долг, дифференциация, дотации, межбюджетные отношения, трансферты.

Региональные управленческо-экономические системы формировались в сложных условиях политической и экономической трансформации, что, безусловно, не могло не привести к возникновению и росту территориальных диспропорций. С 2000 г. в России наблюдается макроэкономический подъем, следствием которого должно было стать снижение проблемы социально-экономической дифференциации регионов.

Во временном интервале с 2000 по 2019 гг. неоднократно менялись механизмы бюджетного регулирования, направленные на повышение эффективности функционирования бюджетной системы страны и ее региональных подсистем. Одним из ключевых направлений бюджетной политики было и остается повышение бюджетной эффективности на всех уровнях управле- ния - принцип, предполагающий оптимальное соотношение бюджетных доходов и расходов в рамках установленных за участниками бюджетного процесса полномочий с целью достижения заданных результатов.

Обеспечение бюджетной устойчивости в последние годы становится все более сложным процессом ввиду усилившейся цикличности экономических спадов, что оказывает существенное влияние на формирование доходов региональных бюджетных систем. Примечательно, что наименьшим рискам, связанным с экономическими колебаниями, подвержены регионы, являющиеся получателями дотаций (2/3 от общего числа). Более ощутимые потери наблюдаются у сильных регионов, экономика которых адекватно реагирует на конъюнктурные, политические, экономические трансформации.

\footnotetext{
* Статья подготовлена по результатам исследований, выполненных за счет бюджетных средств по государственному заданию Финансового университета при Правительстве Российской Федерации.
} 
Бюджетная обеспеченность отражает степень покрытия бюджетными доходами расходных обязательств публично-правовых образований [12]. Практически за весь период постсоветского развития бюджетная обеспеченность большинства субъектов РФ находилась в пределах 10-80\%. К числу наиболее обеспеченных регионов по соотношению бюджетных доходов и расходов были и остаются интенсивно развивающиеся территории: г. Москва и СанктПетербург, Московская область, Республика Татарстан и др., составляющие десятую часть от общего числа регионов России.

Уровень дифференциации бюджетной обеспеченности субъектов РФ имеет высокую степень расхождений, показатели которых по разным коэффициентам приведены в таблице 1 .

Приведенные данные характеризуют высокую степень территориального неравенства по показателю бюджетной обеспеченности, как в целом по субъектам, так и в границах каждой группы. Среднее значение по уровню бюджетной обеспеченности составило в целом по РФ $79,6 \%$, при этом, степень отрицательного отклонения у 7 регионов составила $-3,5$ раз, у 25 регионов - 1,6 раз, 18 регионов - 1,1 раза. Превышение показателя бюджетной обеспеченности от среднего по стране значения составило: у 20 регионов $-1,04$ раз, у 9 регионов $-1,47$ раз, у 6 регионов $-2,7$ раз.

Отметим, что эталонным значением признается $100 \%$-й уровень бюджетной обеспеченности, когда расходные обязательства полностью покрываются бюджетными доходами. Соответственно, только 15 регионов демонстрируют полное покрытие своих расходных обязательств, остальные 70 субъектов находятся в отрицательной зоне. Отрыв регионов-лидеров (г. Москва, Тюменская область, Ямало-Ненецкий АО, Ханты-Мансийский АО, г. Санкт-Петербург, Сахалинская область), уровень бюджетной обеспеченности которых в значительной степени превосходит соответствующие показатели по остальным пяти группам составляет 13,84 раз.

Чтобы исключить влияние самых высоких и самых низких значений, корректнее уровень бюджетной обеспеченности оценивать по медианным показателям. Средний уровень бюджетной обеспеченности по медианной величине составляет в целом по России 72,7\%. Однако, 32 региона находятся на уровне существенно ниже среднего медианного значения по стране, 18 регионов приближены к среднему значению.

Использование различных коэффициентов для оценки степени расхождений регионов по уровню бюджетной обеспеченности может содержать разные значения отклонений, но совершенно очевидно, что асимметрия существует, и что самое важное, имеет более скрытые формы, ведущие к ее усилению.

Это позволяет сформулировать несколько предварительных выводов:

1 - уровень территориального неравенства сохраняется, более того, углубляется, поскольку хозяйственный потенциал страны все больше перемещается и концентрируется в единичных экономически сильных регионах;

2 - уровень бюджетной обеспеченности имеет высокую степень разброса показателей по регионам, что определяет необходимость межбюджетного выравнивания;

3 - большая часть регионов имеет низкие финансовые возможности обеспечения текущих расходных обязательств, что исключает (ограничивает) возможность направлять средства на развитие экономического потенциала.

Таблица 1. Показатели уровня бюджетной обеспеченности субъектов РФ за 2017 г. в границах ранжирования до распределения дотаций

\begin{tabular}{|l|c|c|c|c|}
\hline $\begin{array}{c}\text { Шкала ранжирования } \\
\text { (в \%) }\end{array}$ & $\begin{array}{c}\text { Количество субъек- } \\
\text { тов РФ (ед.) }\end{array}$ & $\begin{array}{c}\text { Средний показа- } \\
\text { тель по группе (в \%) }\end{array}$ & $\begin{array}{c}\text { Медианный пока- } \\
\text { затель } \\
\text { по группе (в \%) }\end{array}$ & $\begin{array}{c}\text { Коэффициент соот- } \\
\text { ношения БОтах к } \\
\text { БОтіп } \\
\text { («размаха») }\end{array}$ \\
\hline 1 - от 150 и выше & 6 & 214,67 & 173,7 & 1,64 \\
\hline 2 от 100 до 150 & 9 & 117,1 & 114,8 & 1,27 \\
\hline 3- от 80 до 100 & 20 & 82,44 & 87,6 & 1,16 \\
\hline 4 - от 60 до 80 & 18 & 71,75 & 72,2 & 1,29 \\
\hline 5 - от 30 до 60 & 25 & 49,7 & 51,1 & 1,88 \\
\hline 6 - ниже 30 & 7 & 22,75 & 23,7 & 1,44 \\
\hline В целом по РФ & $\mathbf{8 5}$ & $\mathbf{7 9 , 6}$ & $\mathbf{7 2 , 7}$ & $\mathbf{1 3 , 8 4}$ \\
\hline
\end{tabular}

Расчеты авторов по данным Министерства финансов РФ [9] 
Наличие глубоких диспропорций бюджетной обеспеченности российских регионов приводит к необходимости ее выравнивания посредством задействования механизма межбюджетных трансфертов.

Механизм межбюджетных трансфертов, установленный БК РФ, предполагает использование нескольких инструментов, основным из которых выступают дотации из федерального бюджета, выделяемые на выравнивание бюджетной обеспеченности регионов с низкими возможностями генерировать собственные бюджетные доходы. Порядок их расчета и распределения осуществляется на основании Методики [10] и опирается на оценку налогового потенциала и индекса бюджетных расходов территорий.

Согласно теории, трансфертному механизму в основном отводятся две функции - выравнивающая и стимулирующая [4]. Российский трансфертный механизм, как свидетельствуют данные, приведенные выше, использует преимущественно функцию выравнивания, не создавая стимулов наращивания налогового потенциала для укрепления бюджетов территорий.

Данный вывод исходит из того, что соотношение регионов до и после выравнивания, не меняется. Принцип «сохранения рангов» при распределении дотаций до 2008 г. был закреплен в Бюджетном кодексе РФ как обязательное требование, впоследствии утратившим силу. Допущение возможности изменения ранга региона после предоставления дотаций приводит к снижению мотиваций у других регионов в наращивании собственных бюджетных доходов. На протяжении последних лет число регионов, являющихся получателями дотаций растет.

Динамика изменения статуса регионов России по уровню бюджетной обеспеченности транслирует разнонаправленные и интересные тенденции: в 2000 г. количество регионовдоноров составляло 19 ед., в 2006 г. - 25 ед. (самое высокое значение за период - на фоне роста не- фтяной конъюнктуры и действующего до 2008 г. налогово-бюджетного механизма), в 2015 г. количество регионов-доноров существенно сократилось - до 14 ед., в 2019 г. их осталось уже 13. Сокращению числа регионов-доноров, начиная с 2014 г. способствовало несколько факторов: экономический кризис 2014 г. (падение цен на нефть, введение санкций и т.д.), централизация на федеральном уровне НДПИ и налога на прибыль организаций (изменение пропорции распределения в 2017 г.), снижение налоговых поступлений по бюджетообразующим налоговым источникам на фоне экономических спадов.

При этом, если в 2006 г. 25 регионов обеспечивали до 80\% налоговых доходов консолидированных региональных бюджетов, в 2015 г. 14 регионов около 60\%, то в 2019 г. на долю 13 регионов-доноров приходилось уже более $60 \%$ к общему объему мобилизованных налоговых доходов, 72,9\% - в общем объеме налогов, отчисляемых данными регионами в федеральный бюджет и 52,5\% составила их доля в налоговых доходах суммарного значения консолидированных региональных бюджетов.

Это демонстрирует ярко выраженную тенденцию концентрации налоговых доходов в федеральном бюджете с обратно пропорциональным снижением налоговой составляющей как в регионах-лидерах, так и в остальных регионах России по удельному весу (позже мы вернемся к проблеме налогового распределения и обеспечения региональных бюджетов налоговыми доходами).

Политика централизации налоговых доходов на федеральном уровне приводит к необходимости компенсации выпадающих доходов для поддержания относительной сбалансированности бюджетной обеспеченности регионов. Состав межбюджетных трансфертов разнообразен и содержит множество форм финансовой поддержки, основными из которых выступают дотации, субсидии, субвенции.

Таблица 2. Количество регионов, получателей дотаций за период с 2000 по 2019 гг.

\begin{tabular}{|l|c|c|c|c|}
\hline \multicolumn{1}{|c|}{ Показатель } & 2000 & 2006 & 2015 & 2019 \\
\hline Количество регионов, не получающих дотации & 19 & 25 & 14 & 13 \\
\hline $\begin{array}{l}\text { Субъекты РФ, доля дотаций в собственных доходах которых } \\
\text { не превышала 10\% }\end{array}$ & 20 & 34 & 34 & 35 \\
\hline $\begin{array}{l}\text { Субъекты РФ, доля дотаций в собственных доходах которых } \\
\text { составила от 10 до 40\% }\end{array}$ & 31 & 28 & 28 & 28 \\
\hline $\begin{array}{l}\text { Субъекты РФ, доля дотаций в собственных доходах которых } \\
\text { превышала 40\% }\end{array}$ & 7 & 7 & 8 & 8 \\
\hline
\end{tabular}

*Данные Министерства финансов РФ [9] 
Таблица 3. Состав и структура межбюджетных трансфертов в динамике*

\begin{tabular}{|l|c|c|c|c|c|}
\hline \multicolumn{1}{|c|}{ Показатель } & 2016 & 2017 & 2018 & 2019 & $\begin{array}{c}\text { Отклонения } \\
2019 \text { к 2016 в \% }\end{array}$ \\
\hline МБТ всего, млрд. руб. & 1474,8 & 1533,5 & 1719,6 & 2387,2 & 161,8 \\
\hline в \% к ВВП & 1,78 & 1,66 & 1,7 & 2,2 & х \\
\hline В том числе & & & & & 143,9 \\
\hline Дотации & 641,7 & 738,2 & 832,0 & 924,0 & х \\
\hline в \% к общей сумме МБТ & 43,51 & 48,14 & 48,4 & 38,37 & 169,2 \\
\hline Субсидии & 328,9 & 349,4 & 397,0 & 556,6 & х \\
\hline в \% к МБТ & 22,30 & 22,79 & 23,1 & 23,3 & 129,6 \\
\hline Субвенции & 305,9 & 303,7 & 309,3 & 396,6 & х \\
\hline в \% к МБТ & 20,75 & 20,07 & 18,0 & 16,6 & 257,6 \\
\hline Прочие МБТ & 198,2 & 137,9 & 181,4 & 510,0 & х \\
\hline в \% к МБТ & 13,4 & 9,0 & 10,5 & 21,4 & \\
\hline
\end{tabular}

*Составлено по данным Министерства финансов РФ

* Основные направления налоговой, бюджетной и таможенно-тарифной политики на 2021 г. и на плановый период 2022-2023 годов.

Режим доступа: http://www.consultant.ru/document/cons_doc_LAW_364178/

Исследуя особенности предоставления межбюджетных трансфертов за последние несколько лет, отметим, что их общий объем демонстрирует тенденцию роста, составившего за период $161,8 \%$. Ведущую роль в их структуре сохраняют дотации, объем которых за период увеличился с 641,7 млрд.руб до 924,0 млрд.руб. на 43,9\%. В 2019 г. отмечается сокращение удельного веса дотаций (с 43,51\% до 38,37\%) в общем объеме трансфертов, что вызвано возрастанием доли иных межбюджетных трансфертов.

Примерно равные доли составляли до 2019 г. субсидии и субвенции, но за период доля субвенций сократилась на фоне роста иных межбюджетных трансфертов. В целом отмечается положительная динамика роста по всем видам финансовой поддержки регионов из федерального центра.

Интенсивное использование различных форм финансовой поддержки регионов (к настоящему времени их насчитывается более 150) искажает реальную картину порядка формирования собственных доходов региональных бюджетных систем, поскольку осуществляется в несколько этапов в процессе утверждения федерального бюджета на очередной финансовый год и по большому перечню направлений финансовой помощи [5]. В представленной выше таблице отсутствуют такие финансовые рычаги, как дополнительные индивидуальные отчисления части акцизов по дифференцированным нормативам (устанавливаются ежегодно), бюд- жетные кредиты, а также прочие трансферты, направляемые на финансирование отдельных расходных обязательств. В данном контексте имеет значение не столько объемы предоставляемых трансфертов, сколько качество используемого механизма распределения.

Предоставление дотаций на выравнивание бюджетной обеспеченности, равно как и других видов целевых федеральных трансфертов, обусловлено рядом декларируемых в программных документах требований: повышение финансовой устойчивости убыточных регионов за счет наращивания экономического и налогового потенциала, оптимизации расходных обязательств и др. Стимулирующий эффект дотаций заложен в формулу расчета размера их предоставления, поскольку основан на соотношении налогового потенциала (без учета региональных налоговых льгот) и индекса бюджетных расходов (соотношение расходов к численности постоянно-проживающего на территории населения). Соответственно, регионы - получатели дотаций, исходя из понимания, что снижение уровня их бюджетный обеспеченности не будет монотонно поддерживаться финансированием из федерального центра, должны приложить все усилия для укрепления собственного налогового потенциала. Однако этот эффект может сработать только в регионах 1-го критерия выравнивания, уровень дотаций в собственных доходах которых, не превышает 10\% (34 региона).

Исходя из того, что на протяжении послед- 
них лет сохраняется устойчивое количество дотационных регионов, причем по группам каждого критерия их состав также не меняется, следует заключить, что стимулирующий эффект межбюджетного финансирования отсутствует, либо очень слабо выражен. Число дотационных регионов в России сохраняется высоким на протяжении всех лет пост реформенного развития России. Все 72 субъекта РФ, являющимися получателями дотаций, охватывают более 85\% территории страны, на их территориях проживает более $75 \%$ всего населения.

Дестимулирующий характер межбюджетного выравнивания подтверждается еще и фактом того, что темпы роста дотаций и общего объема межбюджетных трансфертов (149,3\% и 161,8\% соответственно), опережают темпы роста совокупных налоговых доходов регионов (темп роста с поправкой на инфляцию в среднем составляет за аналогичный период не более $125 \%$ *).

Отсутствие стимулов к укреплению собственных бюджетных доходов субъектов РФ непременно приводит к снижению консолидации интересов между регионами-донорами и регионами-реципиентами.

Очевидно, что механизм межбюджетного выравнивания сложен, содержит множество форм и способов поддержания бюджетной обеспеченности регионов, но не решает проблемы дифференциации и низкой доходности их подавляющего числа.

Особую озабоченность вызывает высокая степень зарегулированности бюджетного процесса, выступающей одной из форм контроля со стороны федеральных властей. Исполнение субфедеральных бюджетов встроено в жесткую систему нормативов, показателей, индикаторов, условий и требований, как по доходным полномочиям, так и по расходным обязательствам. Самостоятельность регионов в вопросах бюджетного регулирования сведена к минимуму.

Выделенные проблемы позволяют сформулировать подходы к выработке нового механизма межбюджетных отношений, основанных на новой налогово-бюджетной конструкции.

В современных условиях вектор равномерного и поступательного пространственного развития направлен не на выравнивание социально-экономических показателей отдельных территорий, образующих целостную эконо- мическую систему в национальных границах, а на обеспечение конкурентоспособности каждого элемента системы. В российских реалиях это станет возможным при кардинальном изменении действующей модели бюджетной системы и межбюджетного регулирования.

Вопрос бюджетной эффективности стоит перед разными странами давно и довольно остро, так как ограниченность бюджетных ресурсов всегда сопровождается необходимостью их рационального и продуктивного использования. Любые траты должны приносить результат - в виде социального, экономического, экологического, управленческого и иных видов эффектов. В бюджетной сфере наиболее сложно в большинстве случаев провести количественную оценку достигнутых результатов. Этим обусловлено действие множества социальных нормативов и индикаторов, достижение которых в отдельных случаях достаточно иллюзорно. В последние годы активно воплощается концепция построения программного и проектного бюджета. Данный показатель стал одним из критериев эффективности управления региональными финансами.

В этой связи представляется, что формирование новой бюджетной модели на всех уровнях управления, не только возможно, но и необходимо с позиции более эффективного управления государственными финансовыми ресурсами и повышения качества предоставления государственных услуг.

Важно при построении такой модели определить основные факторы:

- приоритеты и цели развития региональных бюджетных систем, как основы и движущей силы обеспечения экономического роста;

- учет территориальной организации хозяйственной деятельности, ее отраслевой специфики, ресурсного обеспечения, специализации и комплексности;

- построение оптимальной организационно-управленческой структуры, институционально отражающей все элементы региональной рыночной системы: социальные, экономические, инновационные, инфраструктурные.

Данная концепция предполагает построение функциональных бюджетов, разделенных по источникам формирования и направлениям использования:

\footnotetext{
* По данным мониторинга субъектов РФ и муниципальных образований Министерства финансов РФ. Режим доступа: https://minfin.gov.ru/
} 
1 - операционный бюджет, за счет которого будет продолжено финансирование системы государственного управления и социальной сферы, с соблюдением ключевого требования быть минимально достаточным для успешного управления всей системой;

2 - инвестиционный бюджет, средства которого будут направляться на достижение долгосрочных целей социально-экономического развития территорий, объединив реализуемые государственные программы и национальные проекты.

3 - социальный бюджет, его функции могут выполнять и суверенные фоны, формируемые за счет различных источников финансирования, в том числе и межбюджетных трансфертов (субсидий, субвенций).

Разграничение бюджетов по функциональному признаку позволит сфокусироваться на целях и результатах их функционирования, создав следующие преимущества:
- прозрачность и простота в управлении;

- детализация плановых заданий и фактического исполнения в плотной увязке с достигаемыми результатами;

- учет территориальных особенностей и охват всех сфер деятельности.

Завершая исследование уровня бюджетной обеспеченности регионов и проблем, порождаемых действующим налогово-бюджетным механизмом, отметим, что их разрешение возможно только при согласованном между центром и субъектами комплексном подходе по устранению всех перечисленных выше недостатков, построении более прозрачной и эффективной модели межбюджетного регулирования и реформирования действующей системы налогообложения. Важным при этом сохраняется разработка мер повышения экономического потенциала территорий, как основополагающего условия обеспечения темпов экономического роста и конкурентоспособности.

\section{Библиографический список}

1. Агузарова Ф.С., Токаева С.К. Налоговые доходы бюджетной системы Российской Федерации: особенности формирования на всех уровнях власти / Монография. Владикавказ. 2018. С. 160.

2. Бишенов А.А., Иттиева Л. Х. Анализ распределения выравнивающих дотаций для бюджетов субъектов Российской Федерации. Электронный ресурс. Режим доступа: https://doi.org/10.24182/2073-9885-2020-13-3106-117, дата обращения: 18.10.2021. С. 106-117.

3. Бюджетный кодекс Российской Федерации от 31.07.1998 N 145-Ф3 (ред. от 01.07.2021, с изм. от 15.07.2021) (с изм. и доп., вступ. в силу с 12.07.2021). Электронный ресурс. Режим доступа: http:/www.consultant.ru/ document/cons_doc_LAW_19702/, дата обращения: 14.10.2021 г.

4. Лавровский Б. Л. Территориальная дифференциация и подходы к ее ослаблению в Российской Федерации // Экономический журнал ВШЭ. - 2013. - № 4. - С. 524-537.

5. Морозов О.Г.Бирюков А.Г., Васильев М.А. Статистика межрегиональных различий и состояние бюджетной системы Российской Федерации // Статистика и экономика. Т. 16. № 4. 2019 г. С.73-89. Электронный ресурс. Режим доступа: https://statecon.rea.ru/jour/article, дата обращения 10.10.2021 г.

6. Налоговый кодекс Российской Федерации (НК РФ) от 31 июля 1998 года N 146-Ф3 (ред. от от 02.07.2021 N 305-Ф3). Электронный ресурс. Режим доступа: http://www.consultant.ru/document/cons_doc_LAW_19671/, дата обращения: 14.10 .2021 г.

7. Официальный сайт Счетной палаты РФ. Электронный ресурс. Режим доступа: https://ach.gov.ru/checks/ schetnaya-palata-predlagaet, дата обращения: 8.10.2021 г.

8. Официальный сайт Федеральной службы государственной статистики РФ. Электронный ресурс. Режим доступа: https://rosstat.gov.ru/, дата обращения: 11.10.2021 г.

9. Официальный сайт Министерства финансов РФ. Электронный ресурс. Режим доступа: https://minfin.gov.ru/ $\mathrm{ru} /$, дата обращения 14.10.2021 г.

10. Постановление Правительства РФ от 22.11.2004 N 670 (ред. от 24.12.2020) «О распределении дотаций на выравнивание бюджетной обеспеченности субъектов Российской Федерации» (вместе с «Методикой распределения дотаций на выравнивание бюджетной обеспеченности субъектов Российской Федерации»). Электронный ресурс. Режим доступа: https://rulaws.ru/goverment/Postanovlenie-Pravitelstva-RFot-22.11.2004-N-670/, дата обращения: 14.10.2021 г.

11. Тадтаева В.В., Туаева Л.А. Пути развития доходной базы консолидированного бюджета Республики Северная Осетия-Алания // Экономика и предпринимательство. 2015. № 9(62). С. 460-465.

12. Токаева С.К., Тогузова, И.З., Туаева Л. А. Основные подходы к оценке устойчивости бюджетов субъектов РФ // Экономика и управление. Т. 20. № 6 (176). 2020 г. С. 576-583. 